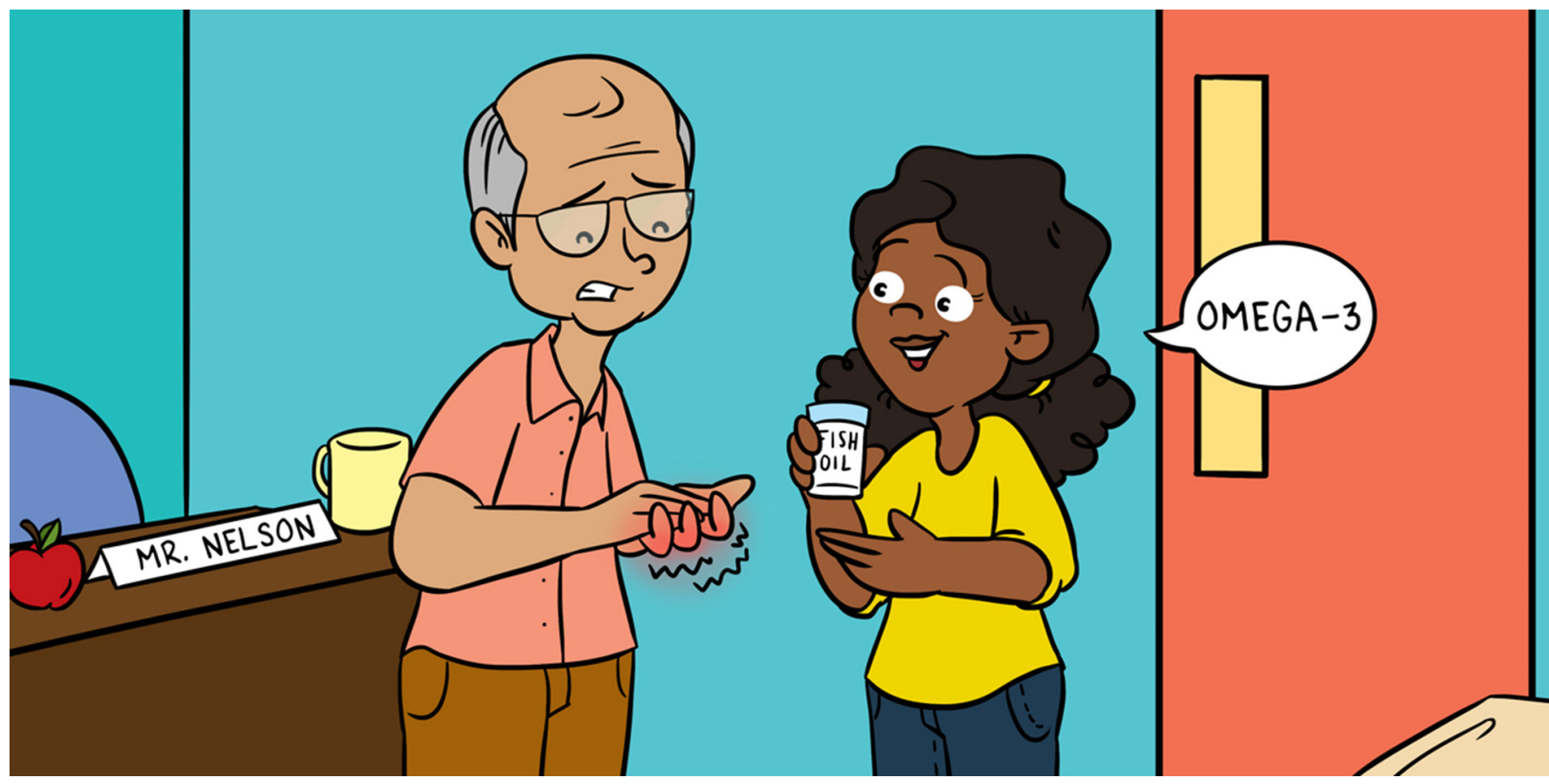

\title{
OMEGA-3 FATTY ACIDS AND INFLAMMATION-YOU ARE WHAT YOU EAT!
}

\section{Kathryn A. Wierenga ${ }^{1,2^{*}}$ and James J. Pestka ${ }^{2,3}$}

${ }^{1}$ Department of Biochemistry and Molecular Biology, Michigan State University, East Lansing, MI, United States

${ }^{2}$ Institute for Integrative Toxicology, Michigan State University, East Lansing, MI, United States

${ }^{3}$ Department of Food Science and Human Nutrition, Michigan State University, East Lansing, MI, United States

\section{YOUNG REVIEWER:}

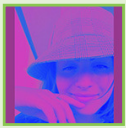

ANNA

AGE: 14

\section{FATTY ACIDS}

The building blocks of fat found in the food we eat and in our bodies and cells. There are different types of fatty acids, including saturated fatty acids, monounsaturated fatty acids, and polyunsaturated fatty acids.
Have you ever heard the phrase, "You are what you eat?" Of course, if you eat a donut, you will not actually turn into a donut-but bits and pieces of what we eat do become parts of us! In this article, we will talk about how the fatty acids in our cells can help protect us from various diseases by controlling inflammation. Specifically, we will focus on food components called omega-3 polyunsaturated fatty acids, which are most abundant in seafood. We will talk about how eating foods rich in omega-3s increases the levels of omega-3s in your cell membranes and may protect against several diseases that are associated with uncontrolled inflammation.

\section{INTRODUCTION TO FATTY ACIDS}

Fatty acids are found in most of the food we eat. Fatty acids are also part of every cell in our bodies, and they are major building blocks in the cell membrane (Figure 1A). Fatty acids can come in 
Figure 1

Fatty acids and the foods in which they can be found. (A) Fatty acids are an important part of the cell membrane. (B) The chemical structure of a saturated fatty acid has no double bonds. (C) Monounsaturated fatty acids contain only one double bond. $(D, E)$ Omega- 6 and omega- 3 fatty acids are polyunsaturated fatty acids (PUFAs), meaning they have multiple double bonds, creating more bends in their structures (created with BioRender.com)

POLYUNSATURATED FATTY ACIDS

(PUFAS)

Fatty acids with more than one double bond.

\section{ESSENTIAL FATTY} ACIDS

Fatty acids that must be consumed in the diet because our cells cannot make them on their own.

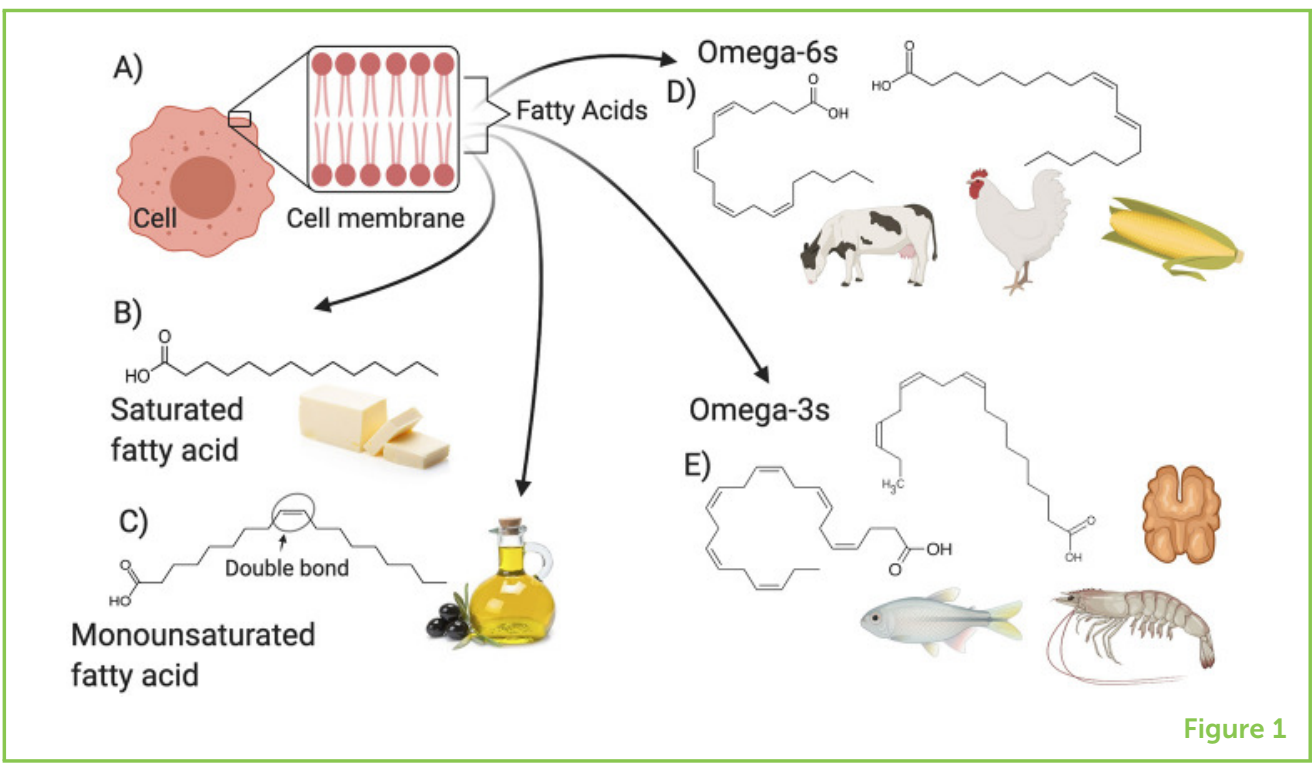

all sorts of shapes and sizes-some are long, some are short, some are crooked, and some are straight. If you look at the nutrition facts on food labels, sometimes you will see that "total fat" is separated into saturated, monounsaturated, and polyunsaturated fatty acids. The level of saturation in a fatty acid is based on the number of connections called double bonds in the chemical structure of the fatty acid chain, which determines how straight or crooked the fatty acid is. Bonds are the tiny connections between atoms that hold them together to form molecules, and double bonds are stronger, shorter bonds than single bonds. When simple models of chemical structures are drawn, single bonds are represented with a single line and double bonds with a double line. Saturated fatty acids have no double bonds (Figure 1B), and monounsaturated fatty acids have only one double bond (Figure 1C). Polyunsaturated fatty acids (PUFAs) have lots of double bonds, and therefore are more crooked (Figures 1D,E).

Our bodies can make many fatty acids on their own, but there are a few special classes of PUFAs that we cannot make: omega- 3 and omega- 6 PUFAs. These PUFAs are very similar to each other but have a slightly different shape, based on the locations of their double bonds. Because these fats need to be consumed in the diet, they are known as essential fatty acids. Omega- 6 s are found in many foods that come from land animals, like chicken and beef, and are also found in certain plants, like corn and soy (Figure 1B). Omega-3s are more common in marine animals, like fish and shrimp, and are found in plants like flaxseed and walnuts (Figure 1C). While it is necessary to get both types of fat in our diets, studies have shown that it is very important to balance the amount of omega-3s and omega-6s we eat. 
Figure 2

The Omega-3 Index measures the levels of omega-3 PUFAs in the red blood cell membrane. The Omega-3 Index was measured in people who added 4 extra servings of fish per week to their diets. This dietary change significantly increased the Omega- 3 Index meaning the omega-3 PUFAs they ate in their food increased the omega-3 PUFAs in their cell membranes [image credit: Harris et al. [1], Table 1].

\section{OMEGA-3 INDEX}

The amount of EPA and DHA, the two most abundant omega-3 PUFAs, in the red blood cell membrane.

\section{INFLAMMATION}

The activation of the immune system to fight against an infection. Chronic inflammation, which is inflammation that continues when it is no longer necessary, is believed to contribute to many diseases.

\section{Change in Omega-3 Index over time}

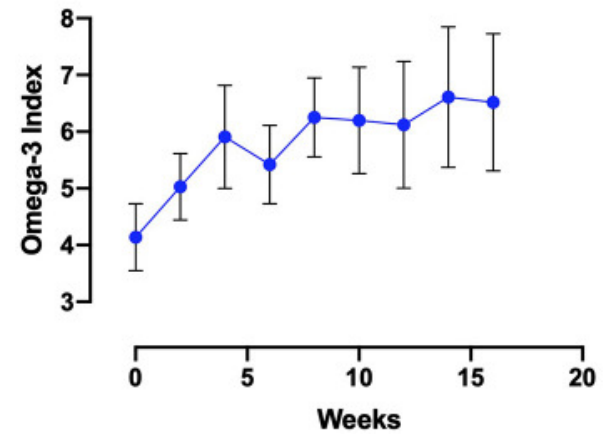

Figure 2

\section{THE JOURNEY OF A FATTY ACID}

When we eat foods that contain fat, enzymes in the digestive tract break down the fat into individual fatty acids, which get transferred across the wall of the intestines and repackaged into little fat globules that are transported all throughout the body. A lot of this fat is used for energy, but it can also be used to remodel cell membranes. This is especially true for essential fatty acids. Since we cannot make these ourselves, the omega-3s and omega-6s in the cell membrane must come from our diets. This means the fatty acids in the hamburger you ate for lunch can end up in the membranes of your cells!

How do scientists know this? Studies have been performed in both animals and humans, in which subjects are fed diets that contain different levels of omega-3s and omega-6s. Scientists can then take a tiny bit of blood-just a few drops-and measure the fatty acids that make up the red blood cell membranes. The omega- 3 levels in the blood are often called the Omega-3 Index. After a few weeks of increasing the amount of omega-3s in the diet, the Omega-3 Index also starts to increase (Figure 2) [1].

\section{FATTY ACIDS AND INFLAMMATION}

Studies have shown that increasing the levels of omega-3s in our cell membranes may protect against or help to reduce the symptoms of certain diseases. For example, scientists have discovered that increasing the Omega-3 Index can decrease the risk of death in patients with heart disease and can decrease swollen joints in patients with rheumatoid arthritis $[2,3]$. One thing that these ailments have in common is inflammation, which can be reduced by omega-3s.

In many cases, inflammation is a very good thing [4]. It is the process that occurs when the immune system fights back against an infection. Have you ever gotten a splinter, and noticed that the area is swollen, redder than the rest of your skin, and maybe a bit painful? This is 


\section{Figure 3}

Most Americans have a dramatic imbalance of omega-6s and omega-3s in their diets. The proper ratio of omega-6s to omega-3s can keep inflammation in check, but when this ratio is skewed heavily toward omega-6s, inflammatory diseases such as heart disease, asthma, and arthritis are more likely (created with BioRender.com).

\section{METABOLITES}

Small molecules made or used when the body breaks down food, drugs, chemicals, or its own tissue.

\section{Recommended Omega- 6 to Omega- 3 ratio is $2: 1$}

\section{Estimated American diet \\ Omega- 6 to Omega-3 ratio is $>20: 1$ !}

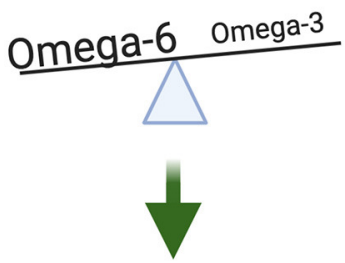

Normal levels of inflammation
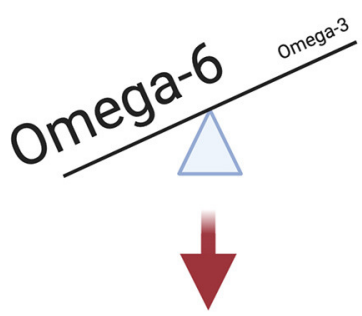

Uncontrolled inflammation

inflammation! Your immune system is working hard to fight off any bacteria that may have entered your body when you got the splinter. Normally, once your immune system has eliminated the threat of an infection, the area will heal and return to normal. Unfortunately, sometimes this process goes haywire and inflammation can continue when it is not necessary. This is referred to as chronic inflammation, and it can have many negative effects, including permanent damage to the tissue. Medical concerns including heart disease, arthritis, and even some cancers are associated with chronic inflammation, which is why it is so important to keep inflammation from getting out of control.

Scientists have shown that a high Omega-3 Index can help protect against chronic or uncontrolled inflammation. Specifically, maintaining a proper balance of omega-3s and omega- $6 \mathrm{~s}$ in the diet is critical for maintaining healthy omega-3 levels in the cell membranes. It is important to remember that nutrition is all about balance: we do not want to consume only omega-3s, but instead we should try to eat a healthy proportion of both omega-3s and omega-6s. Scientists recommend that we eat only about two times more omega-6s than omega-3s, but it is estimated that most Americans consume more than 20 times more omega-6s than omega-3s (Figure 3)! This imbalance in dietary fatty acids may contribute to the chronic inflammatory diseases prevalent in individuals consuming a Western-style diet [5].

How do omega-3s help reduce inflammation? This is a question that scientists are still trying to understand, but there are a few discoveries that could explain this [2]. First, having more omega-3s in their cell membranes allows cells to make more omega-3-derived metabolites, many of which can turn off the inflammatory response and turn on a healing response that helps the tissue or cell repair any damage caused by inflammation. Another way omega-3s reduce inflammation could be through changes in types and amounts of microorganisms that live 


\section{GUT MICROBIOTA}

The microorganisms that live inside the gastrointestinal tract. in the gut, called the gut microbiota. It is well-known that what we choose to eat influences the microorganisms that live in the gut and that these organisms can influence our health. Scientists have found that consuming omega- 3 fatty acids changes the types of microbes in the gut, but it is not yet known exactly how these changes to the microbiota influence inflammation [6]. These are just two of many potential ways that omega-3s can protect against inflammation.

\section{CONCLUSION}

We have discussed how an increase in the Omega-3 Index is associated with a decreased risk of some diseases because omega-3s can protect against inflammation. It does not just stop there! High Omega-3 Indexes are associated with all sorts of health benefits that affect both adults and kids, including better sleep and quicker muscle recovery after exercise. Importantly, we can improve our Omega-3 Index by making healthy choices about the types of fats we consume. Eating a diet rich in omega-3s means that you become rich in omega-3s. In the case of essential fatty acids, you truly are what you eat, and this has a direct impact on your health!

\section{REFERENCES}

1. Harris, W. S., Pottala, J. V., Sands, S. A., and Jones, P. G. 2007. Comparison of the effects of fish and fish-oil capsules on the $\mathrm{n} 3$ fatty acid content of blood cells and plasma phospholipids. Am. J. Clin. Nutr. 86:1621-5. doi: 10.1093/ajcn/ 86.5.1621

2. Calder, P. C. 2017. Omega-3 fatty acids and inflammatory processes: from molecules to man. Biochem. Soc. Trans. 45:1105-15. doi: 10.1042/BST201 60474

3. O'Keefe, E. L., Harris, W. S., DiNicolantonio, J. J., Elagizi, A., Milani, R. V., Lavie, C. J., et al. 2019. Sea change for marine omega-3s: randomized trials show fish oil reduces cardiovascular events. Mayo Clin Proc. 94:2524-33. doi: 10.1016/j. mayocp.2019.04.027

4. Montero-Melendez, T. 2018. May inflammation be with you! Front Young Minds. 6:51. doi: 10.3389/frym.2018.00051

5. Simopoulos, A. P. 2016. An increase in the omega-6/omega-3 fatty acid ratio increases the risk for obesity. Nutrients. 8:128. doi: 10.3390/nu8030128

6. Menni, C., Zierer, J., Pallister, T., Jackson, M. A., Long, T., Mohney, R. P., et al. 2017. Omega-3 fatty acids correlate with gut microbiome diversity and production of $\mathrm{N}$-carbamylglutamate in middle aged and elderly women. Sci Rep. 7:11079. doi: 10.1038/s41598-017-10382-2

SUBMITTED: 31 August 2020; ACCEPTED: 26 July 2021;

PUBLISHED ONLINE: 24 August 2021.

EDITED BY: Kelly Westlake, University of Maryland, United States 


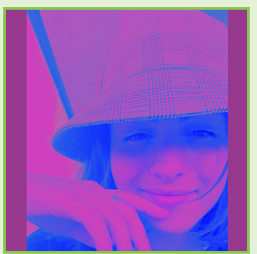

CITATION: Wierenga KA and Pestka JJ (2021) Omega-3 Fatty Acids and Inflammation-You Are What You Eat! Front. Young Minds 9:601068. doi: 10.3389/ frym.2021.601068

CONFLICT OF INTEREST: The authors declare that the research was conducted in the absence of any commercial or financial relationships that could be construed as a potential conflict of interest.

COPYRIGHT @ 2021 Wierenga and Pestka. This is an open-access article distributed under the terms of the Creative Commons Attribution License (CC BY). The use, distribution or reproduction in other forums is permitted, provided the original author(s) and the copyright owner(s) are credited and that the original publication in this journal is cited, in accordance with accepted academic practice. No use, distribution or reproduction is permitted which does not comply with these terms.

\section{YOUNG REVIEWER}

\section{ANNA, AGE: 14}

I am a student in the Greater Pittsburgh area. I love going to Science Olympiad, spending time with my friends, playing lacrosse, listening to music, and making art. I also love traveling and have been to many places in the world, my favorites being Paris, South Africa, and Australia. I love good food and am addicted to taking pictures of sunsets.

\section{AUTHORS}

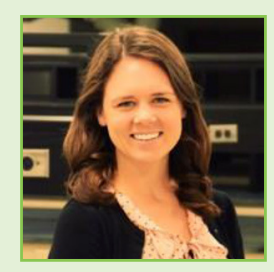

\section{KATHRYN A. WIERENGA}

Kate is a PhD student at Michigan State University. She has always enjoyed learning biology, especially the immune system. Kate works in Dr. Pestka's lab where she studies how omega- 3 fatty acids protect against inflammation. In her free time, Kate enjoys any outdoor activity, especially running! *royerkat@msu.edu

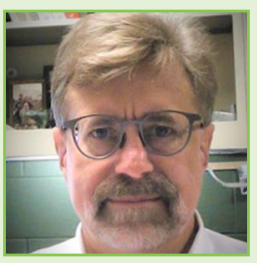

\section{JAMES J. PESTKA}

Dr. James Pestka is a researcher at Michigan University. Research in Dr. Pestka's lab investigates how things we are exposed to in the environment influence the immune system and the development of autoimmune disease. Studies in Dr. Pestka's lab have found that omega- 3 fatty acids can protect animals from inflammation caused by inhaling toxic silica dust. In his free time, he enjoys spending time kayaking on Lake Huron. 